\title{
Smartphones, smart spaces? O uso de mídias locativas no espaço urbano em Curitiba, Brasil
}

Tharsila Dallabona-Fariniuk. Pontifícia Universidade Católica do Paraná, Curitiba, Brasil.

Rodrigo Firmino. Pontifícia Universidade Católica do Paraná, Curitiba, Brasil.

RESUMo | O uso de dispositivos móveis cresceu consideravelmente nos últimos anos. Essas tecnologias tornam-se responsáveis por fundir, em um mesmo universo, várias formas de comunicação das pessoas com o mundo, criando situaçôes de dependência e de pertencimento. Mais recentemente, a gestão urbana vem utilizando smartphones e aplicativos como ferramentas auxiliares na identificação e resolução de demandas. Questiona-se como o uso desses dispositivos influenciam a utilização do espaço urbano, em termos de reconhecimento, de permanência e de valorização. É objetivo desta pesquisa caracterizar influências do uso de smartphones no meio urbano, a partir do levantamento de possíveis impactos relacionados ao uso de aplicativos. A pesquisa, baseada em análise de discurso simplificada, categorizou aplicativos utilizando-os como objetos elucidativos para os conceitos teóricos. Concluiu-se, que, neste recorte, o conceitos de espaço ampliado é reconhecível, presente não apenas nas relaçóes entre pessoas e tecnologias, mas também no incentivo ou desestímulo de utilização dos espaços.

PALAVRAS-CHAVE | TiCs, espaço público, transformaçôes sócio-territoriais.

ABSTRACT | In recent years, the use of mobile devices has grown considerably. This technology has become responsible for merging different communication systems, into a single universe, creating situations of dependence and belonging. More recently, urban management has been using smartphones and applications as auxiliary tools in identifying and solving urban demands. In this paper, the authors question how the use of these devices influences the use of urban space, in terms of recognition, permanence and valorization. This research aims to characterize influences of the use of smartphones in the urban environment, from the identification of possible impacts related to the use of apps. This research, based on simplified discourse analysis, categorizes applications using them as enlightening objects for theoretical concepts. Results show that the concept of augmented space is recognizable, which is present not only in the relations between people and technologies, but also in the incentive or discouragement of the use of space.

KEYWORDS| ICTs, public space, socio-territorial transformations.

Recibido el 16 de mayo de 2017, aprobado el 10 de septiembre de 2017

E-mails: T. Dallabona-Fariniuk, tharsilamd@hotmail.com | R. Firmino, rodrigo.firmino@pucpr.br 


\section{Introduçáo}

A partir dos anos 1990, especialmente, o advento de novas tecnologias resultou em uma revoluçáo informacional. Com o passar do tempo essas Tecnologias de Informação e Comunicação (TICs) tornaram-se cada vez mais pessoais, cada vez menores, e cada vez mais invasivas. Essas são características que continuam a se acentuar, fazendo com que as Tics não possam mais ser consideradas separadamente das dinâmicas de vida em sociedade e do comportamento humano. Nesse contexto, até mesmo o planejamento urbano passou a dar mais reconhecimento às tecnologias como influentes nas atividades sociais, econômicas e culturais. A disseminação de dispositivos móveis como smartphones e tablets - constituídos de dispositivos que os transferem a capacidade de geolocalização por GPS ou triangulação de antes dos celulares, as chamadas mídias locativas - foi um dos elementos fundamentais deste processo.

Nos últimos anos, o uso de dispositivos móveis cresceu consideravelmente. Os dados da empresa de tecnologia CISco (2016) mostram que em 2015 havia aproximadamente 7,6 bilhóes de aparelhos conectados à internet no mundo, e que este número deve chegar a 11,6 bilhóes até 2020. Na América do Norte e no oeste europeu a proporção de uso desses dispositivos representará aproximadamente 2,8 aparelhos per capita, e na América Latina, aproximadamente 1,5 aparelhos per capita. Também no Brasil o crescimento é expressivo. Em 2014 o número de usuários de aparelhos celulares chegava próximo à $80 \%$ da população, o que representou um aumento de $142,8 \%$ em relação ao ano de 2005 . Além disso, a utilização da internet apenas em celulares vem ultrapassando a utilização em outros meios domésticos, como desktops e notebooks, em especial na região Norte do país (Pesquisa Nacional por Amostra de Domicílios [PNAD], 2016).

O incremento da tecnologia nos dispositivos móveis permitiu o surgimento de funcionalidades que, entre outros fatores, também auxiliam e influenciam a vida em cidades: sistemas de localização, georreferenciamento, fotografias, troca de mensagens, etc. Neste processo cria-se o que Boullier (2014) chama de ecossistema de dados pessoais, quando a consciência de "estar conectado" full time passa a ter muita importância. Assim, os aparelhos celulares tornam-se responsáveis por fundir, em um mesmo universo, várias das formas de comunicação das pessoas com o mundo: pertences pessoais, localizaçóes, transaçôes financeiras, etc. Desse modo, os dispositivos criam situaçóes de dependência e de pertencimento que se assemelham a "envelopes" comunicacionais, ou bolhas imaginárias capazes de encapsular uma série de atividades, transaçóes, círculos sociais e comportamentos, individualizados ao redor de cada pessoa e potencializados por um único dispositivo de acesso, comunicaçáo e processamento. Isto é parte do que Boullier (2014) denomina "Habitele", um conceito composto pela associação dos termos "hábito", "habitat" e "telemática", que representa a articulação entre o uso das mídias locativas e o comportamento humano.

Nesse contexto, o espaço urbano sofre também alteraçóes, pois deixa de ser essencialmente um espaço físico de circulação, habitação, lazer e trabalho, e passa a agregar também características de inserção de informaçóes, com grandes volumes 
de dados (Big Data) e com a construção de redes infocomunicacionais. As funçôes presentes nos dispositivos (especialmente aplicativos) passam a ser agentes potenciais de transformação no meio, inclusive com a transformação de relaçóes territoriais de posse, pertencimento, localização e movimento de corpos e mentes no espaço, físico e informacional.

Como exemplo, pode-se citar a alteração da permanência das pessoas nos lugares a partir da oferta ou não de rede WiFi (Lemos \& Firmino, 2015). Ou, ainda, a demanda crescente de segurança e monitoramento, que faz com que aplicativos sejam formulados e disponibilizados no sentido de permitir controle sobre o espaço e reconhecimento das localidades. É o que Farman (2012), denomina "vigilância locativa”, em que a participação do usuário é fundamental para a construçấo do espaço social. Ainda mais recentemente, a disseminação de jogos de realidade virtual baseados em estruturas construídas também vem possibilitando novas formas de apropriação e utilização das áreas urbanas.

A noção de apropriação do espaço está diretamente relacionada à construção de identidades urbanas, temas esses trabalhados pelo filósofo e historiador francês Michel de Certeau em meados dos anos 1980. De acordo com o autor (2002), a apropriação está relacionada ao modo como cada um situa os outros em relação a si mesmo, agregando valores espaciais, sociais, políticos e culturais; e esse processo foi enfatizado e ampliado com a circulação de informaçóes e com a comunicação. A dificuldade de se contextualizar esse fenômeno reside no fato de que é muito complexo combinar todas as individualidades, os vários "mundos" em um mesmo objeto a ser tratado.

A concepção de Certeau sobre o espaço urbano, de acordo com Dosse (2004), constitui-se por três eixos: a produção de um espaço que é próprio de cada um, as tradiçóes que são organizadas sem um tempo definido, em um "não-tempo", e a construção da cidade como um "sujeito" universal. Dosse afirma que, a partir disso, a noção espacial de Certeau é muito mais antropológica e existencialista, na qual a cidade é traduzida pela experiência, pelo caminhar e pela apropriação dos cidadãos. Além desses fatores, a utilização de smartphones vem sendo considerada também como uma ferramenta auxiliar de gestão urbana. Seja pela possibilidade de maior alcance de informaçóes sobre a cidade, seja no sentido de orientar a participação cidadã online, a rede de conexões móveis vem sendo objeto de cada vez mais discussóes sobre modos de gerir as cidades. Esse processo é parte do que denomina-se "cidade inteligente", onde o uso intensivo de TICs - para coleta, organização e análise de dados e informaçóes-, associadas a automação de açóes e atividades de organização de infraestrutura e territórios urbanos, protagonizam estratégias de planejamento e gestâo de inúmeras grandes e médias cidades em todas as regióes do globo (Caragliu, Del Bo \& Nijkamp, 2011).

Essas dinâmicas de interação pessoal e tecnológica são parte do chamado "espaço ampliado", um conceito que está associado à ampliação da capacidade comunicacional e do alcance de distâncias, mesmo sem existir deslocamentos geográficos (Firmino, 2011).

Entender as dinâmicas espaciais influenciadas pela invasividade dessas tecnologias constitui um desafio em diversos aspectos. Primeiramente, pela compreensão de 
que o acesso aos dispositivos não é homogêneo, nem quanto à motivação para o uso, nem quanto às distribuiçôes social e geográfica. Em segundo lugar, pela consideração de que a disseminação dessas tecnologias é um processo relativamente recente, em relaçáo ao que representa na linha do tempo do urbanismo. Uma terceira preocupação se relaciona à necessidade de se compreender o reflexo dessas novas interaçôes sociedade/tecnologia nos modos de concepçáo, construção e apropriação do espaço urbano, bem como arriscar uma nova epistemologia do território capaz de abarcar as sobreposiçóes presentes entre as camadas materiais e digitais da atividade de demarcação da ação humana no espaço-tempo.

Ao longo do tempo a indústria do entretenimento buscou refletir, em obras como Matrix (Wachowski \& Wachowski, 1999) e Blade Runner (Scott, 1982), a consolidação, permanência e interferências das tecnologias na sociedade. Essas obras, assim como outras, traduziram as perspectivas e receios atrelados às tecnologias de suas épocas. Mais recentemente, a série de Tv Black Mirror (Brooker, 2011) também levantou essa discussão. Os episódios apresentam diversas situaçóes de uma sociedade totalmente moldada e (re)formulada a partir da pervasividade e tecnológica e da dominância das redes sociais na opiniáo pública e modo de vida das pessoas. De acordo com Sola (2014), a metaficção presente nos episódios permite discussóes críticas sobre a relação tecnologia-consciência e sobre o imaginário social. Essa intenção de mesclar o que é real com sistemas tecnológicos (ficíticios ou não) é o que Duarte, Firmino e Crestani (2015) denominam "fantasmagorias urbanas". São aspectos e ideias que transitam de maneira tênue entre a realidade, a utopia e futuros plausíveis, ou seja, podem representar possibilidades concretas. De acordo com os autores, as fantasmagorias - presentes nestes e em outros tantos produtos de entretenimento - parecem diluir as fronteiras entre sociedade e tecnologia.

Além desses aspectos, deve-se considerar também que a utilização cada vez maior das tecnologias no espaço urbano levanta um debate a respeito da nocividade desse processo. De acordo com Graham e Marvin (1996), abordagens que consideram as tecnologias como solução para todos os problemas urbanos, em um viés quase "futurístico", tendem a ser encapsuladas em estratégias de puro marketing urbano, não necessariamente possuindo um propósito integrador e otimizador. Esse processo pode transformar o espaço urbano na chamada "cidade corporativa", ou "entrepeneur city", na qual busca-se soluçóes para o desenvolvimento a partir de uma lógica empresarial de livre concorrência (Harvey, 2005). Assim, o desenvolvimento urbano seria um caminho que priorizaria o desenvolvimento econômico e "pró-business" e só então seguiria na busca pelo bem-estar social (Peck \& Tickell, 2002).

Nesse contexto, uma das questóes emergentes é de que forma o uso de smartphones pode influenciar, efetivamente, a utilização do espaço urbano, em termos de apropriação geográfica, de reconhecimento, de permanência e de valorização. A investigação aqui relatada origina-se nesse questionamento, e objetiva caracterizar influências do uso de smartphones no meio urbano, associando-as ao conceito de espaço ampliado e de habitele, a partir do levantamento de possíveis impactos relacionados ao uso de aplicativos e de funçóes relacionadas.

Com isso, a partir de um estudo realizado em 2013, buscou-se analisar 110 aplicativos com geolocalizaçáo, categorizando-os segundo conceitos que serão 
apresentados ao longo deste artigo. A discussão está estruturada, inicialmente, de modo a apresentar um levantamento conceitual relativo aos smartphones e à dinâmica do espaço informacional constituído no meio urbano. Em seguida, é apresentada a metodologia utilizada para seleção e categorização dos aplicativos. Parte-se então para a apresentação dos resultados, discussão e análise, e, por fim, apresenta-se as conclusóes.

\section{Mídias locativas e a codificaçáo do espaço}

As tecnologias comunicacionais permitindo gerenciamento de informações, regulação e monitoramento em tempo real são parte do que se entende por cidade inteligente ou smart city. No campo da gestáo urbana percebe-se hoje diversas possibilidades narrativas e de discurso que reificam e fetichizam tecnologias inteligentes de vigilância e gestáo como soluçóes para quase todos os aspectos da vida urbana contemporânea, depositando na eficiência de processos a marca da cidade neoliberal e inteligente. Segundo Luque-Ayala e Marvin (2015), eficiência, conexão sem interrupçóes e o sonho do controle total tornam-se condiçóes fundamentais para a existência de um suposto urbanismo inteligente, presente no próprio imaginário da smart city.

Diversos estudos focam nos modelos inovadores e na produção de iniciativas smart, mas são poucos os que possuem uma perspectiva mais crítica dos efeitos sócio-espaciais produzidos pelo digital (Kitchin, 2014).

Os artefatos tecnológicos, de acordo com Duarte e Firmino (2012), representam a sociedade, e não podem ser dela desvinculados. As tecnologias, segundo os autores, são "tão humanas quanto os humanos são tecnológicos" (p. 70). Desde o momento em que aprendemos a codificar coisas pela combinação de números, as tecnologias digitais parecem ter influenciado dramaticamente a maneira com que interagimos entre nós mesmos, com o meio que nos envolve (inclusive o meio construído), e com as próprias tecnologias (inclusive com o recente surgimento da Internet das Coisas, em que objetos podem trocar informaçóes e dados entre si para executar tarefas e açôes pré-definidas, mediaçóes algorítmicas, etc.). Somos transformados em representaçôes de uma possibilidade de ser, em números, códigos e dados em sistemas interconectados, de maneira que as TICs passam a ser o mais invasivo grupo de tecnologias já desenvolvido, em que tudo tende a ter um microchip como parte de sua estrutura física e a carregar capacidades computacionais e comunicacionais, estando em todos os lugares, afetando todos os sistemas e a grande maioria das pessoas, e potencializadas pelos pequenos aparelhos agregados aos nossos corpos e funçóes cotidianas.

Essas tecnologias, impregnadas e cada vez menos perceptíveis no meio, criam o chamado espaço ubíquo. No início dos anos 1990 esse tema já era tratado por Weiser (1991), que utilizou o termo "computação ubíqua" para designar a possibilidade de interação com um computador em qualquer lugar. Para isso, seriam necessários três elementos tecnológicos: aparelhos (computadores) com preço acessível, redes de ligação entre eles e softwares de aplicação ubíqua (permitindo acesso em qualquer lugar, a qualquer tempo). Torna-se praticamente impossível, hoje, isolar-se 
deste ambiente de total codificação, já que quase todas as atividades e transações que sustentam o modo de vida contemporâneo são mediadas por uma certa desmaterialização de pessoas, ações, agenciamento, objetos e relaçóes, em informaçóes associadas a sistemas ou redes específicas.

Quando os artefatos permitem a vinculação de um conjunto de dados informacionais a uma localidade, são denominados mídias locativas, tais como smartphones e tablets (Lemos, 2008). Estas são, ainda, estabelecidas por funcionalidades de mapeamento, geoprocessamento, localização, vigilância e monitoramento, a partir da vinculação de um conteúdo digital (Santaella, 2008). De acordo com Bambozzi (2009), locativo significa rastreabilidade, inclusive com tendências a ser intrusivo, e permitindo, também, ser ferramenta para açóes de vigilância e de disciplina.

As funçóes locativas presentes nos smartphones e tablets, bem como suas características de miniaturização e portabilidade, criam um modo de viver nômade e um entendimento transitório dos lugares. Assim, a especificidade de um lugar gera concentraçáo e demanda envolvimento, processo este que se torna maleável com o conteúdo digital (Bambozzi, 2011).

Santaella (2008) reforça essa idéia afirmando que algumas funçôes presentes nas mídias locativas (como envio de mensagens, tags, fotos e vídeos) podem ser associadas a determinados pontos da cidade, o que configura o que a autora chama de anotaçóes urbanas. Esse processo pervasivo, que alia recursos computacionais ao espaço, reflete características de mobilidade, de identidade, de enraizamento, de personalização e de precisão.

Nesse cenário ocorre uma transformação dos componentes do espaço. As mídias locativas têm a capacidade de transformar lugares em territórios, ${ }^{1}$ a partir da inserção de controle e limites, e de transformar territórios em lugares, a partir do compartilhamento de vivências pessoais. Desse modo, pode-se dizer que em cada conexão e em cada ação realizada, conforme signos e atributos que nela incidirem, há a possibilidade de "lugarizações" e "territorializaçôes".

Assim, as experiências permitidas pelas novas tecnologias tendem a tornar o espaço mais complexo, devido à quantidade e frequência da comunicação e das trocas de informaçóes e dados. As informaçóes, hoje, têm capacidade de serem transmitidas de forma instantânea, o que cria a idéia da ação em tempo real, do just in time. Mas essas açóes demandam tanta eficiência e precisão no mundo atual que deve-se considerar paralelamente a isso a noção do chamado just in place. Essa instantaneidade de açóes permite que as açóes sejam globais (Santos, 2008). Allen (2012) afirma que a quantidade de eventos -e informaçóes- é táo grande que causam a dissociação da pessoa do espaço real ou autêntico. Nesse sentido, náo somente existe esta separação como também a inserção do indivíduo numa rede de informações que não está relacionada a um único local.

Além de fomentar a constituição de novas redes, a inserção das TICs fez com que a sociedade passasse por um processo de alteração de conceitos de interatividade. A interatividade ocorre à medida em que duas ou mais partes comunicadoras agem

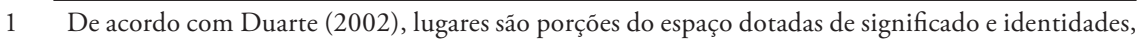
enquanto territórios são as porçôes do espaço com valores morais e culturais compartilhados. 
umas sobre as outras em três níveis: (i) o nível do controle ativo, quando há ação voluntária do comunicador, (ii) o nível da comunicação bidirecional e (iii) o nível da sincronicidade (Liu \& Shrum, 2002).

Em um novo contexto de acessibilidade, interatividade e virtualidade, surgiu a possibilidade de estar em mais de um espaço ao mesmo tempo. Gil (2007) explica que as redes agregam interfaces interativas, que fazem com a que a noção de virtualidade coexista com a noção de tempo real, e as direçóes que este processo toma são imprevisíveis. Dessa forma, o espaço se distanciou do conceito que o estabelecia como locus das trocas materiais para ser conceituado, além disto, a justaposição de diferentes contextos e realidades. Os aspectos que conferiram ao espaço extensão e velocidade não eliminaram, no entanto, as dinâmicas espaciais tradicionais, mas esta ampliação mostra que como conceito e modelo, o entendimento anterior das relaçôes espaciais não é suficiente para caracterizar a nova realidade.

Alguns autores denominam esse novo entendimento espacial como "ciberespaço". De acordo com Lemos (2013a, p. 127), o termo ciberespaço é originário da obra Neuromancer, escrita em 1984 pelo escritor de ficção científica William Gibson. Esse autor considerava o ciberspaço um espaço "não físico ou territorial composto por um conjunto de redes de computadores através das quais todas as informaçóes (sob as suas mais diversas formas) circulam.” Na visão de Wertheim (2001, p. 167), o ciberespaço é um “fenômeno emergente', algo que é mais que a soma de suas partes", sendo também um "subproduto tecnológico da física”, que permite sua existência por meio dos chips, satélites, telas, fibras óticas e eletricidade. Portanto, não há uma total separação entre o espaço físico e o ciberespaço. Mesmo assim, segundo a autora, este não está contido naquele. O ciberespaço, conforme Wertheim, é mais do que um espaço de dados, não é apenas informação; é também instrumento para a interação, para a comunicação, para o entretenimento e para a criação do que ela chama de "alter egos" (p.170). A autora afirma ainda que quanto mais os meios de comunicação, as empresas, os cursos e os jogos estiverem disponíveis on-line, mais haverá a obrigação de frequentarmos os ambientes ciberespaciais. O valor do ciberespaço, neste sentido, não está na possibilidade de multiplicidade dos "eus", mas sim no incentivo a uma apreensão e a uma expansividade do "eu uno".

Esse processo de chaveamento entre o uso das novas tecnologias -em especial os smartphones- traduz-se no conceito de "habitele" (Boullier, 2014). O termo deriva da composição das palavras "hábito" e "habitat" com "telemática". O ambiente em que vivemos, de acordo com o conceito, está permeado por tecnologias ubíquas que ampliam a capacidade de comunicação e constroem ligaçóes entre o espaço e o ciberespaço, o presencial e o digital. Habitele seria uma camada espacial individual que acompanha o homem contemporâneo a partir de seu acesso a transaçóes, atividades, relacionamentos, círculos sociais, e identidades, por meio de dispositivos móveis capazes de convergir todos estes níveis de interação em um único artefato tecnológico, que pode ser representado com uma extensão do corpo e do habitat deste corpo. Assim, ao acessar suas transaçóes bancárias pelo smartphone ao mesmo tempo em que conversa com amigos em um café, checa sua linha do tempo em mídias sociais, e envia mensagens a familiares, uma pessoa estaria utilizando 
as capacidades multipresenciais, comunicacionais e espaciais que Boullier (2014) batizou de habitele.

\section{Confluências conceituais}

A noção de um espaço ampliado, que associa o físico ao digital, e que está em constante transformação sugere o destaque de três características principais, coexistentes e derivadas uma das outras: (i) a própria noção de transformação e/ou alteração do espaço físico, a partir da indicação de ampliação e do encurtamento de distâncias permitidas pela tecnologia; (ii) a ampliação da capacidade comunicacional, permitida pela infraestrutura física e digital, sempre renovada pelo modus operandi das novas tecnologias; e (iii) a sobreposição e justaposição de informações, permitida pelas outras duas características, a partir da possibilidade de incremento das conexốes entre pessoas e dados.

Nas mídias locativas, em especial nos smartphones, essas características também podem ser observadas e tornam-se ainda mais visíveis com as constantes atualizaçóes tecnológicas.

A noção de transformação e ampliação do espaço, enquanto meio de deslocamento físico, pode ser observada por meio das funcionalidades de geolocalizaçáo (GPS, mapeamentos, check-in, etc.), associadas ao comportamento a elas relacionados.

A idéia de ampliação da capacidade comunicacional reflete-se na possibilidade de trocas de mensagens de som, vídeo e texto. É um universo de compartilhamento que vai além do modus operandi do telefone propriamente dito, e se estende para os mais diversos tipos de redes sociais acessíveis no aparelho celular. Essas funcionalidades, não por acaso, são as que mais atualizam-se em termos tecnológicos, tornando-se inclusive obsoletas em curtos períodos de tempo.

Finalmente, a sobreposição e justaposição de informaçôes é uma característica derivada das anteriores, e reflete-se em praticamente todas as funcionalidades das mídias locativas, a partir da inserção em uma ampla e complexa rede de dados. Um exemplo prático dessa característica são as funções de realidade aumentada, atualmente presente em diversos programas e aplicativos. A realidade aumentada ocorre quando conteúdos digitais são disponibilizados como um reflexo do conteúdo do tempo real (Graham, Zook \& Boulton, 2013). Para isto, em geral pode-se usar, por exemplo, a câmera do celular, que referencia determinados pontos físicos associando-os e combinando-os a objetos digitais. Dessa forma, o usuário pode experimentar novas relaçóes com o espaço, que se torna infinito em termos de direçóes e relacionamentos (Gonçalves, 2011).

Essa amálgama de possibilidades infocomunicacionais é ainda potencializada por um fenômeno conhecido como Internet das Coisas. Este fenômeno ocorre devido à criação de uma rede global de objetos que estáo conectados por meio de programas e protocolos, o que representa uma significativa alteração na relação entre pessoas e tecnologias (INFSO [Information Society], 2008). É um novo paradigma informacional (Vega-Barbas et al., 2012), capaz de dar "vida" aos objetos tecnológicos e aos algoritmos, fazendo-os comunicar-se, tomar decisôes e adaptar-se sem que haja, necessariamente, o controle humano (Lemos, 2013b). 
A relação entre essas características e suas funcionalidades práticas sugerem que a forma de utilização de aplicativos é um indicativo das possibilidades de interação na cidade, podendo auxiliar a compreender algumas das associaçóes homem-tecnologia-espaço. Além disso, as características convergem com a proposta conceitual de Habitele, que propóe o chaveamento entre os comportamentos humanos e o uso de aparelhos celulares.

\section{Explorando aplicativos locativos e espaço urbano em Curitiba (Brasil); o método}

O estudo aqui descrito procurou caracterizar possíveis influências do uso de smartphones no meio urbano da cidade de Curitiba (Brasil) e região, a partir do entendimento de como os conceitos de espaço ampliado e habitele permeiam essa discussão. Para isso, optou-se por um levantamento de aplicativos (e suas respectivas funçóes e usos) que, analisados individual e coletivamente, contribuíssem para a indicação de possíveis impactos urbanos relacionados ao uso dos mesmos.

O levantamento iniciou com uma coleta de dados realizada por meio de pesquisa em bases de dados online. Os locais pesquisados foram:

- plataformas de comercialização de aplicativos (segundo seus sistemas operacionais): Apple (iOS), Google Play (Android) e Microsoft App (sistema Windows), os quais foram selecionados por apresentarem atualização constante dos produtos comercializados, além de informaçóes sobre os mais utilizados, avaliaçóes e impressóes dos usuários;

- blogs e portais voltados para a divulgação de novidades relacionadas à tecnologia e mídias digitais, escolhidos por possuírem a característica de rapidez da disseminação de informação, em geral antes da divulgação em fóruns científicos e plataformas acadêmicas.

Observou-se que estas fontes de busca apresentam os aplicativos disponíveis setorizados em temáticas. Assim, foram selecionados aqueles relacionados de forma mais aderente aos conceitos estudados. Optou-se, portanto, por aplicativos presentes nas seguintes categorias: cidades; urbanismo; urbano; locais; deslocamentos; navegação; e mobilidade.

A partir da aplicação deste filtro, observou-se um grande número de opções presentes em cada um destes setores. Desta maneira, a escolha e posterior catalogação dos aplicativos (em planilha) seguiu os seguintes critérios:

- Aplicativos utilizados na região de Curitiba, ou desenvolvidos especialmente nestes locais, possibilitando assim, um recorte geográfico e uma maior aderência ao local de origem da pesquisa.

- Aplicativos que apresentassem maior utilização (segundo dados estatísticos de download apresentados nas plataformas de comercialização, ou que também tivessem sido citados em outras plataformas).

Essa busca (e consequente catalogação) foi realizada até a saturação, ou seja, interrompeu-se a partir do esgotamento de novidades e da repetição de citaçóes (em um 
mesmo site ou plataforma e também entre eles). Deste modo, procurou-se valorizar a diversidade de funcionalidades mais do que a quantidade. Nesse momento de descontinuidade da coleta de dados, 110 aplicativos estavam catalogados.

A análise de dados foi realizada em duas etapas. Na primeira delas, a partir de uma avaliação simplificada de conteúdo baseada na descrição técnica e comentários dos aplicativos. Bardin (2011) comenta que essa ferramenta pode ser utilizada quando a intenção da pesquisa é interpretar ou simplesmente descrever o conteúdo de qualquer tipo de documento. Essa análise procurou indicativos de palavraschave e termos mais utilizados. Dessa maneira, duas formas de categorização foram estabelecidas. Em primeiro lugar, quanto à procedência do aplicativo: bottom-up (oriunda de iniciativas particular, popular ou ongs) ou top-down (fomentada, criada ou patrocinada total ou parcialmente por órgãos e instituiçóes governamentais).

Em segundo lugar, quanto à destinaçáo do aplicativo, em termos de setor de interesse público e/ou grupo do qual faz parte. Nesta etapa, seis categorias foram observadas:

- Mobilidade: Aplicativos voltados à circulação urbana, trânsito e meios de transporte, também relacionados aos temas "deriva”, "deslocamento" e "localização";

- Cidadania: Aplicativos com objetivo de promover a interação entre gestão e cidadãos, a partir do engajamento social, denúncia de problemas urbanos, preservação do meio, reclamaçóes e sugestóes.

- Turismo: Aplicativos destinados à atividade turística com roteiros, informaçóes do setor hoteleiro ou plataformas de banco de dados de determinada localidade;

- Serviços: Aplicativos destinados à troca de informações entre cidadãos e empresas, a partir da disponibilização de informaçóes sobre o terceiro setor (vagas, consultas, ofertas, preços, entre outros).

- Educação: Aplicativos destinados à aulas à distância, servindo como material de apoio e/ou enriquecimento de conteúdo didático.

- Relacionamentos: Aplicativos voltados para o compartilhamento de mensagens e para redes sociais, objetivando comunicação.

A segunda etapa de análise considerou o grupo de dados obtidos sob a ótica das características presentes no conceito de espaço ampliado, apresentadas anteriormente, e foi realizada no sentindo de identificar articulaçóes entre o conceito e as funcionalidades presentes nas mídias locativas. Os aplicativos foram analisados segundo as três características fundamentais, conforme apresenta o tabela 1. 
TABELA I | Articulaçôes entre conceitos e funcionalidades

\begin{tabular}{|c|c|c|}
\hline CARACTERÍSTICAS & $\begin{array}{c}\text { APLICAÇÃO EM MÍDIAS } \\
\text { LOCATIVAS }\end{array}$ & AUTORES \\
\hline $\begin{array}{l}\text { Transformação e/ou ampliação } \\
\text { da noção do espaço físico }\end{array}$ & $\begin{array}{l}\text { Geolocalização, mapeamento e } \\
\text { rastreabilidade. }\end{array}$ & \multirow{3}{*}{$\begin{array}{l}\text { Allen (2012) } \\
\text { Bambozzi (2009) } \\
\text { Duarte \& Firmino (2012) } \\
\text { Gil (2007) } \\
\text { Gonçalves (2011) } \\
\text { Graham et al. (2012) } \\
\text { Lemos (2007, 2013a, 2013b) } \\
\text { Santaella (2008) } \\
\text { Wertheim (2001) }\end{array}$} \\
\hline $\begin{array}{l}\text { Ampliação da capacidade } \\
\text { comunicacional }\end{array}$ & $\begin{array}{l}\text { Comunicação, compartilhamento } \\
\text { de informaçóes e mensagens. }\end{array}$ & \\
\hline $\begin{array}{l}\text { Sobreposição/Justaposição de } \\
\text { informaçôes }\end{array}$ & Realidade Aumentada. & \\
\hline
\end{tabular}

FONTE ELABORAÇÃo PRÓPRIA (2016)

\section{Aplicativos urbanos e a cidade como experimentaçáo}

Os 110 aplicativos resultantes da coleta de dados foram primeiramente analisados quanto à procedência. Observou-se que $82 \%$ deles originam-se de projetos ou iniciativas bottom-up, ou seja, partindo da comunidade em geral. Os 19\% restantes são resultantes de açôes governamentais e iniciativa pública (top-down).

As categorias de estudo, definidas a partir de sua emergência no processo de avaliação representam agrupamentos, como unidades de análise. Foi possível observar que a maior parte dos aplicativos analisados está relacionada à mobilidade (44,5\%), e em segundo lugar, os voltados para ações de cidadania (21\%), conforme apresentam as figuras 1 e 2 .

A segunda etapa de análise procurou observar os aplicativos selecionados sob a ótica das três características do espaço ampliado, no intuito de identificar as articulaçôes entre os conceitos e as funcionalidades da própria mídia. A relembrar, foram considerados os elementos: (i) geolocalização, mapeamento e rastreabilidade; (ii) comunicação, compartilhamento de informaçôes e mensagens, e (iii) realidade aumentada.

A classificação nesses três grupos permitiu identificar que, embora as características possam estar presentes individualmente em determinados aplicativos, é comum que apareçam agrupadas (como ocorre em 41,8\% dos casos analisados). Essa combinação sugere que o incremento na complexidade pode contribuir para uma maior interatividade. A interatividade é um fenômeno estabelecido a partir do momento em que existe disposição e demanda para a participaçáo e para a intervenção (Silva, 2009). Na prática, o que ocorre é que estes aplicativos incentivam a participação do usuário de modo vertical, no sentido de serem provedores ou receptores das informações; e de modo horizontal, por possibilitarem a veiculação de informaçóes das mais diversas formas: texto, imagem, áudio e vídeo. 
FIGURA I | Distribuição de aplicativos conforme categorias de análise

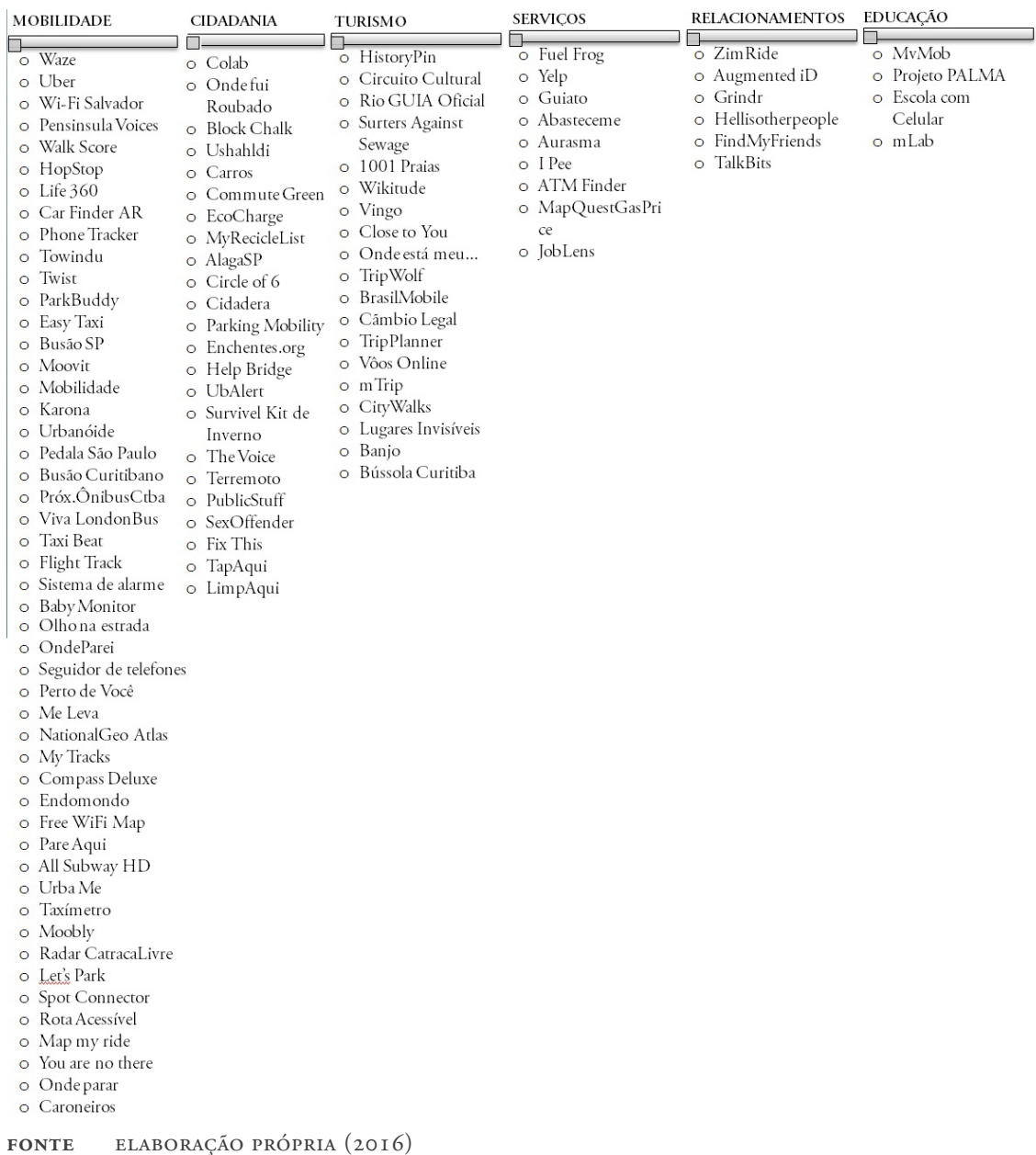

\section{FIGURA 2 Distribuição percentual de aplicativos segundo categorias de análise}

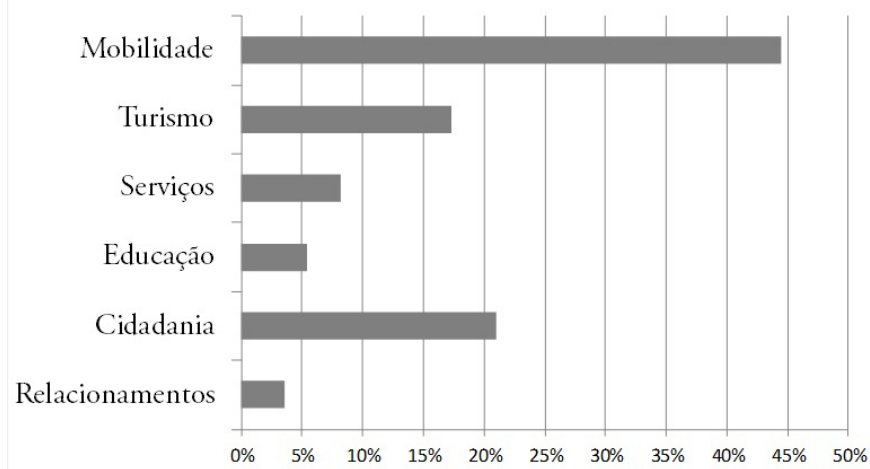

FONTE ELABORAÇÃO PRÓPRIA (20I6) 
A figura 3 foi elaborada de maneira a apresentar, em termos de proporção visual, a participação de cada uma dessas característica no conjunto de aplicativos analisados.

FIGURA 3 | Distribuição dos 110 aplicativos analisados, segundo funcionalidades combinadas, por porcentagem

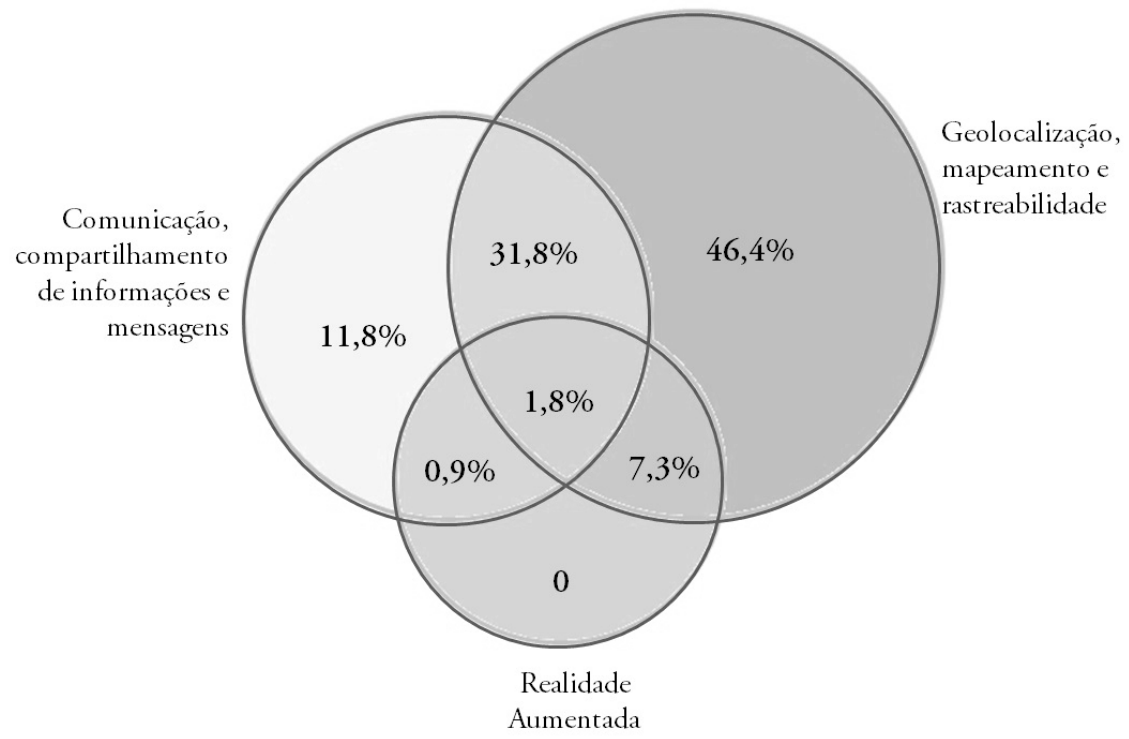

FONTE ELABORAÇÃo PRÓPRIA (20I6)

Observou-se que na maioria deles $(87,3 \%)$ estão presentes as funçôes de geolocalização, mapeamento e rastreabilidade, sendo que $46,4 \%$ do total possui exclusivamente essa função. Os resultados indicam, também, uma concentração significativa de aplicativos com recursos de compartilhamento de informações e mensagens, além de uma tendência a atrelar estas duas aplicabilidades $(31,8 \%)$.

Esse fenômeno pode indicar uma nova forma de apropriação do espaço, o que pode ser chamado de anotaçóes urbanas. Elas são criadas a partir da facilidade de associação de informaçóes-compartilhadas entre usuários-a determinados pontos da cidade, elucidando noçóes de precisão, de mobilidade e de enraizamento. Estes elementos constituem as chamadas anotaçôes urbanas (Santaella, 2008).

Um dos exemplos mais conhecidos, que faz parte da lista de aplicativos estudados, é o Waze. A plataforma oferece serviço de geolocalização para permitir a busca de endereços e a sugestão de rotas, quase como um aparelho de navegação GPS veicular tradicional. A diferença fundamental dessas outras ferramentas reside no fato do aplicativo fornecer camadas de informaçóes que se sobrepóem ao mapa e às rotas em tempo real e pelos próprios usuários. Com isso, o aplicativo é utilizado também para a identificação de problemas de trânsito e para a sugestão de rotas alternativas. Os usuários podem trocar informaçóes a respeito de congestionamentos, acidentes, paradas policiais, obstáculos na pista, entre outras. Essas informaçóes são mapeadas 
com diferentes cores e tags, facilitando a visualização da região como um todo. $\mathrm{O}$ aplicativo vem sendo utilizado, inclusive, pela imprensa, em jornais televisivos e nos sites das emissoras, para informar sobre condiçôes de trânsito nas cidades. O Portal G I Paraná, um dos principais veículos de notícias da cidade de Curitiba, possui uma plataforma online para o aplicativo, o "mapa da velocidade", com atualizaçóes sobre as condições de trânsito em tempo real (GI Paraná RPC, s/data). Uma relação nova estabelecida por esse tipo de aplicativo, entre geolocalização e usuário, é a utilização da ferramenta para o recebimento e gerenciamento de informaçóes sobre o espaço, e não mais apenas o próprio espaço (distribuição de vias e possíveis rotas). As camadas informacionais adicionadas ao espaço transformam completamente a experiência territorial resultante da utilização do aplicativo, principalmente se comparada ao uso do GPS veicular tradicional.

A constante utilização do aplicativo para informar sobre a existência de blitz policiais (e consequente desvio das mesmas) tem levantado debates polêmicos sobre a ética desta utilização. Recentemente, no mês de agosto de 2016, a Comissão de Ciência e Tecnologia da Câmara dos deputados aprovou um projeto de lei que visa transformar em infração de trânsito a utilização de qualquer tipo de tecnologia ou aplicativo que indique a presença de blitz policiais nas cidades (Estadão, 2016). Desse modo, constitui-se um exemplo de implicação jurídico-burocrática a partir da utilização de uma ferramenta tecnológica que influencia a ocupação do espaço urbano. Por outro lado, aplicativos como esse tem a capacidade de informar o usuário sobre situaçóes específicas de momento ou idiossincrasias de certos lugares, que também podem ser a diferença entre a vida e a morte. É o caso, por exemplo, de informaçôes fornecidas sobre vias e rotas que acessam áreas com altos índices de violência e dominadas por facçôes criminosas (o caso de algumas favelas no Rio de Janeiro, por exemplo). Essas áreas podem ser evitadas a partir de rotas alternativas, mas poderiam ser acessadas se o único componente informacional da ferramenta fosse a geolocalizaçáo e o traçado de rotas por vias entre dois pontos espaciais distantes (vários exemplos com casos de morte de turistas entrando certas áreas inadvertidamente são apresentados pela imprensa diuturnamente). ${ }^{2}$

Pode-se observar, ainda, a pouca quantidade de aplicativos que possuem recursos de realidade aumentada, ao mesmo tempo em que todos os que possuem esta funcionalidade estão também associados à geolocalização. Trata-se de uma outra categoria onde são sobrepostas camadas infocomunicacionais ao espaço. Logicamente, esta funcionalidade demanda a associação a um dado local e, a partir deste, são obtidas novas informaçôes em rede. A tendência é que essa forma de tecnologia seja cada vez mais utilizada no futuro, trazendo transformaçóes significativas para a experiência urbana a partir de um processo de hibridização entre o que é físico, construído, e o que está digitalmente disponível.

As categorias de recursos são potencialmente capazes de transformar a experiência urbana, a partir do incremento da relação usuário/aparelho/espaço. Ou seja,

2 Ver, por exemplo, “Turista é morta com tiro após gps leva-la a bairro violento, diz polícia”, gi Santa Catarina, 01/01/2017, disponível em: http://g1.globo.com/sc/santa-catarina/noticia/2017/01/ turista-gaucha-morre-apos-levar-tiro-no-norte-da-ilha.html 
o entendimento comum da cidade muda a partir da infiltração dos espaços informacionais (Duarte \& Firmino, 2008). E à medida que a oferta destas funcionalidades aumenta, é ainda mais significativa a influência sobre a vivência urbana. Isto traduz-se em sensaçôes de descobertas do meio, conforme novos tipos de diálogos e experimentaçóes surgirem no espaço.

Recentemente, o jogo PokémonGo -exemplo de aplicativo que mistura realidade aumentada com comunicação entre usuários- suscitou uma série de questôes sobre formas de reapropriação do meio urbano. Por ser um aplicativo recentemente lançado, não foi incluído nesta pesquisa.

O jogo consiste em "capturar" personagens virtuais a partir do ato de se locomover na cidade física, de forma que quanto mais lugares o jogador visitar, mais personagens poderá colecionar. De acordo com reportagem do The New York Times (2016), o aplicativo permite que pessoas sejam levadas a áreas livres e verdes, além de possibilitar a disseminação de um recurso de realidade aumentada que não demanda aparatos específicos, além do próprio smartphone. Além disso, o jogo também possibilitou oportunidades mercadológicas, a partir da publicidade criada por estabelecimentos privados, que unem o consumo no local com a possibilidade de aumento da pontuação (Pimenta, 2016). No entanto, discute-se também sobre as implicaçóes na segurança dos jogadores, que, a partir deste uso, estáo mais expostos a roubos e acidentes.

Os exemplos citados demonstram novas formas de chaveamento entre as pessoas e os dispositivos, o que contribui para que o espaço urbano seja utilizado, compreendido e re-criado . Isso ocorre, por exemplo, à medida em que a utilização dos aplicativos leva a uma maior permanência no espaço, ou à criação de diferentes interesses que estão associados a determinado local (não necessariamente visíveis, porém virtualmente presentes). Dessa maneira, quando ocorre uma ação humana, ela será refletida digitalmente, por meio do dispositivo, e vice-versa; o espaço físico, materialmente construído, é a estrutura que suporta ambas as açóes e que, invarialmente, também será afetada pela ação.

\section{Consideraçóes finais}

Esta pesquisa buscou caracterizar a relação homem/espaço/artefato tecnológico a partir das influências do uso de smartphones no meio urbano, associando-as ao conceito de espaço ampliado e de habitele. A pesquisa focou suas observaçóes e consideraçóes sobre o tema na cidade de Curitiba, uma das capitais de estado mais importantes do Brasil, conhecida por seu pioneirismo em várias inovaçóes no âmbito do planejamento urbano e mobilidade a partir da segunda metade do século xx.

Conexôes e associaçóes entre tecnologias digitais, espaço e sociedade também estiveram no centro das discussóes lançadas ao longo do texto. Da mesma forma com que ocorre novas formas de experimentação do espaço, tende-se à sofisticação da comunicação entre dados e objetos, que passam a exercer cada vez mais funçóes, automatizando processos. Nesse sentido, a tendência é que os smartphones representem cada vez mais o fenômeno de Internet das Coisas. Ao permitir troca de informaçôes, conversas em mídias sociais e diálogos das mais variadas formas, 
os aplicativos mais recentes exemplificados aqui, não apenas contribuem para a ampliação da capacidade comunicacional como também traduzem a noção de habitele. Isso ocorre porque agregam valores de comunicação entre grupos e de percepçôes individuais, as quais compóem um habitat digital propriamente dito.

Além disso, as funçóes de geolocalização e rastreamento não apenas permitem a sobreposição e a justaposição de informaçóes, como também contribuem para que distâncias e barreiras geográficas sejam diluídas, permitindo a interação entre pessoas e locais fisicamente distantes. Esta mobilidade infocomunicacional faz com que os ambientes de percepçáo e de comportamento individuais -os "envelopes" presentes no conceito de habitele- possam ser enriquecidos por meio dos mecanismos de interação.

Assim, a análise deste conjunto de aplicativos permite a sintetização de algumas idéias fundamentais. Primeiramente, uma nova combinação de modos de entender lugares e territórios a partir da inserção da tecnologia. Os aplicativos são meios potenciais de transformação da ação do e no espaço, pois podem alterar a permanência, o deslocamento, o reconhecimento e a intervenção sobre ele.

Em segundo lugar, há a possibilidade de re-desenhos na dinâmica da tríade homem/espaço/artefato tecnológico. Quando ocorre alteração ou transformação em uma das dimensóes, as outras passarão por um processo de transformação. A associação dessas três dimensôes resulta numa forma de interação que possui como princípios regentes a conexão, o acesso, a comunicação e a intencionalidade. A força dessas relaçôes será maior ou menor conforme a disponibilidade, a oferta e/ou a carência de um ou mais destes princípios. Assim, o fator mais relevante não é o artefato (smartphone, aplicativos) em si, mas a maneira como serve de plataforma e de interface para a potencialização da relação entre pessoas, objetos e o espaço urbano.

Em Curitiba, esse fenômeno pode ser ilustrado pelo aplicativo COLAB, mencionado na categoria "cidadania". O aplicativo permite ao cidadão identificar situaçôes que demandam atuação da prefeitura, enviando fotos, vídeos e mensagens e solicitando o serviço necessário a partir da geração de um protocolo. O serviço foi disponibilizado em 2014 por meio de um contrato entre a prefeitura e o gerenciador da plataforma, e, de acordo com o prefeito da época, foi iniciado visando o desafio de reduzir a distância entre as demandas da população e a capacidade de resposta do poder público (Prefeitura de Curitiba, 2014). A mais recente atualização do site do aplicativo informa que há mais de 12 mil usuários da plataforma na cidade. $\mathrm{O}$ site também apresenta estatísticas a partir do banco de protocolos, as quais indicam que as principais demandas são queixas por estacionamento irregular $(30,6 \%)$ e por buracos nas vias urbanas (8\%). A partir do aplicativo é também possível visualizar as demandas em um mapa (onde se ratifica a questão da associação georreferencial da tecnologia) e as fotos enviadas pelos usuários (Colab.re, s/data).

A gestão urbana, no entanto, nem sempre possui os instrumentos necessários para a correta compreensão e utilização dos dispositivos móveis (e outras tecnologias), ou das informaçóes que neles são veiculadas. Até mesmo a noção de ambientes informacionalmente mais inteligentes é um assunto de trato relativamente recente por gestores urbanos, no Brasil-embora a literatura já trabalhe há vários anos essas questóes. Em resumo, o trato da tecnologia e de seus efeitos no 
espaço exigem constante reformulação e atualização do planejamento urbano em todas as suas dimensôes.

A construção de uma cidade smart (no sentido completo da palavra em inglês, e não apenas inteligente, que deriva de uma tradução literal incompleta) demanda fazer com que as funcionalidades e utilidades produzam uma gestão mais automatizada, com sistemas abertos, e certamente mais participativa e descentralizada. Não se trata, no entanto, de construir uma cidade futurística ou imaginária, pautada por utopias e distopias, mas de compreender e aproveitar os desdobramentos sociotécnicos das conexôes permitidas pelas tecnologias (Kitchin, 2014). Nesse sentido é importante discutir que o aplicativo serve como ferramenta auxiliar da vida urbana, e nâo substitui o papel do diálogo direto entre cidadão e gestor, nem pode ser utilizado como respositor absoluto de serviços oferecidos na cidade.

A inserção dos novos artefatos tecnológicos -os smartphones e aplicativos- no meio urbano muda a forma como ocorre a comunicação entre pessoas e objetos, entre cidadão, arquitetura e cidade. Desse modo, uma parcela significativa do papel do usuário, enquanto cidadão e consumidor, é transformado, orientado, corrigido ou sugerido a partir das informaçôes que são veiculadas na rede. $\mathrm{O}$ urbano concreto, físico e vivenciado no cotidiano, e o urbano informacional convivem e dialogam direta e indiretamente neste processo, compondo um cenário de ricos universos em rede, individuais e coletivos. Não há mais como negar o papel protagonista das tecnologias digitais e todas as ramificaçóes em termos de agenciamento e apropriaçóes socioculturais, na percepção e experiência espacial urbana contemporânea. Essas tecnologias, como um dos elementos histórica e socialmente construídos que compóem nossa urbanidade, participam da definição da relação homem/espaço a partir das interaçóes provocadas entre corpo e espaço, mente e espaço, e redes sociais e espaço. Lugares e territórios são porçóes do espaço apropriados culturalmente, nas quais as formas de apropriação recebem novos contornos pela mediação do uso de aplicativos em smartphones na definição de redes e círculos de convívio social e de açóes que compóem o modo de vida atual nas cidades.

Naturalmente, outras questôes permeiam este debate, como a possível tendência à desvalorização das relaçôes pessoais estabelecidas diretamente, e a efemeridade das estratégias de gestão associadas à tecnologia (já que esta tende a atualizar-se com mais velocidade do que as açóes administrativas e públicas). Essas discussóes, no entanto, podem ser trabalhadas em estudos futuros, considerando abordagens de outras áreas como a sociologia e a antropologia. Cabe, ainda, a ressalva de que este estudo se limita à análise de um recorte quantitativo e temporal, e, portanto, sugerese para estudos futuros a atualização e a ampliação do volume de dados analisados.

Concluiu-se, portanto, que, para este recorte estudado os conceitos-chave trabalhados -espaço ampliado e habitele- são identificáveis e reconhecíveis, estando presentes não apenas nas relaçóes construídas entre pessoas e tecnologias, mas também no incentivo ou desestímulo de utilização dos espaços físicos e informacionais. Além disso, os diversos recursos oferecidos nestes aplicativos, combinados às funcionalidades técnicas dos aparelhos móveis, representam possíveis transformaçóes na mobilidade, de forma a encurtar distâncias entre o espaço físico e o espaço informacional. 
O uso do espaço urbano pode ser, então, enriquecido, com a sobreposição de conteúdos e ação sobre a paisagem, e maiores interaçóes entre os diversos habiteles e espaços ampliados dos quais fazemos parte e compartilhamos em rede, seja ela física ou informacional. Se por um lado, essas associaçóes -espaço, TICs, círculos socioculturais e cidadãos- podem ser estimuladas ou exploradas pelo estado no sentido de se garantir conexóes mais efetivas entre os lugares, suas vivências cotidianas e os projetos urbanos, por outro lado, uma atenção especial deve ser dedicada a processos de inclusão e ampliação do acesso, não somente às próprias tecnologias que fazem parte dos arranjos sociotécnicos descritos aqui (aplicativos e smartphones), como também às formas de utilizá-los de maneira à proporcionar maior diversidade de uso dos espaços públicos, bem como mais interação entre as possíveis percepçóes e apropriações destes mesmos espaços.

\section{Referências bibliográficas}

Allen, P. (2012). Framing, locality and the body in augmented public space. In: A. Aurigi \& F. Cindio (eds.), Augmented urban spaces: articulating the physical and electronic city (pp. 27-39). Burlington: Ashgate,.

Bambozzi, L. (2009). Aproximaçōes arriscadas entre Site specific e artes locativas. In: A. Lemos \& F. Josgrilberg, Comunicação e Mobilidade: Aspectos socioculturais das tecnologias móveis de comunicação no Brasil (pp. 109-201) Salvador: Editora da Universidade Federal da Bahia (EDUfBa).

Bambozzi, L. (2011). O lugar da negociação na mobilidade. In: G. Beiguelman \& J. La Ferla (orgs.), Nomadismos Tecnológicos. Sáo Paulo: Serviço Nacional de Aprendizagem Comercial (sEnAC).

Bardin, L.(2011). Análise de conteúdo. Lisboa: Edições 70.

Boullier, D. (2014). Habitele: mobile technologies reshaping urban life. URBE - Revista Brasileira de Gestão Urbana, editorial seção especial, 6(1), 13-16. from://www2.pucpr. $\mathrm{br} / \mathrm{reol} / \mathrm{pb} /$ index.php/urbe?dd1 $=12397 \& \mathrm{dd} 99=$ view $\& \mathrm{dd} 98=\mathrm{pb}$

Brooker, C. (2011). Black Mirror. [série de televisão]. Londres: Endemol UK.

Caragliu, A. \& Del Bo, C. \& Nijkamp, P. (2011). Smart cities in Europe. Journal of Urban Technology, 18(2), 65-82. http://www.tandfonline.com/doi/ abs/10.1080/10630732.2011.601117?journalCode=cjut20

Certeau, M. de (2002 [1970]), Histoire et structure. In: M. de Certeau, Histoire et psychanalyse. Entre science et fiction (pp.190-191). Paris: Gallimard.

CISCO. (2016). Cisco Visual Networking Index: Mobile Connected Devices, 2015-2020. Cisco vNI Forecast. http://www.cisco.com/c/en/us/solutions/service-provider/visualnetworking-index-vni/vni-inforgraphic.html

Colab.re. (s/data). Resumo de atividades do aplicativo na cidade de Curitiba. https://www.colab. $\mathrm{re} / \mathrm{BR} / \mathrm{PR} / \mathrm{Curitiba}$

Dosse, F. (2004). O espaço habitado segundo Michel de Certeau. ArtCultura, 9, 81-92. http:// www.artcultura.inhis.ufu.br/PDF\%209/ArtCultura\%209_dosse.pdf

Duarte, F. (2002). Crise das Matrizes Espaciais. São Paulo: Perspectiva/Fundação de Amparo à Pesquisa do Estado de São Paulo (fapesp). 
Duarte, F. \& Firmino, R. (2012). Do espaço ampliado ao mundo codificado. In: P. A. Rheingantz \& R. Pedro (orgs.), Qualidade do lugar e cultura contemporânea: controvérsias e ressonâncias em ambientes urbanos (pp. 69-80) . Rio de Janeiro: Universidade Federal do Rio de Janeiro (UfrJ)/Faculdade de Arquitetura e Urbanismo (fau)/ Programa de Pós Graduaçáo em Arquitetura (PROARQ).

Duarte, F., Firmino, R. \& Crestani, A. (2015). Urban phantasmagorias: Cinema and the immanent future of cities. Space and Culture, 18(2), 132-142. http://journals.sagepub. $\mathrm{com} /$ doi/abs/10.1177/1206331214533257?journalCode=saca

Duarte, F. \& Frey, K. (2008). Redes urbanas. In: F. Duarte, C. Quandt \& Q. Souza (orgs.), O tempo das redes. São Paulo: Perspectiva.

Estadão. (2016, August 31). Comissão da Câmara aprova PL que pode proibir função do Waze no Brasil. http://link.estadao.com.br/noticias/cultura-digital,comissao-da-camaraaprova-pl-que-pode-proibir-waze-no-brasil,10000073164

Farman, J. (2012). Mobile interface theory: Embodied space and locative media. New York: Routledge.

Firmino, R. J. (2011). Cidade Ampliada: Desenvolvimento urbano e tecnologiada informação e comunicação. São Paulo: ECidade.

G1Paraná RPC. (s/data). Mapa da velocidade. http://g1.globo.com/pr/parana/transito/radarmapa-da-velocidade-curitiba.html

Gil, A. G. S. (2007). Relações espaciais nas mídias digitais. Ciências \& Cognição, 10, 38-45. http:// pepsic.bvsalud.org/scielo.php?script=sci_arttext\&pid=S1806-58212007000100005

Gonçalves, M. de M. (2011). O uso da realidade aumentada no espaço urbano. Proceedings of the XV Congresso Sigradi, Santa Fé, Argentina. http://papers.cumincad.org/data/works/ att/sigradi2011_271.content.pdf

Graham, M., Zook, M. \& Boulton, A. (2013). Augmented reality in urban places: contested content and the duplicity of code. Transactions, 38(3), 464-479. http://onlinelibrary. wiley.com/doi/10.1111/j.1475-5661.2012.00539.x/full

Graham, M. \& Marvin, S. (1996). Telecommunications and the City: Electronic Spaces, Urban Places. New York: Routledge.

Harvey, D. (2005). A produçâo capitalista do espaço. São Paulo: Annablume.

INFSO (Information Society) [INFso D.4 Networked Enterprise \& RFID / Infso G.2 Micro $\&$ Nanosystems in co-operation with the RFID Working Group of the European Technology Platform on Smart Systems Integration (EPOSs)]. (2008). Internet of things in 2020: a roadmap for the future. European Commission: Information Society and Media. http://www.smart-systems-integration.org/public/documents/publications/ Internet-of-Things_in_2020_EC-EPoSS_Workshop_Report_2008_v3.pdf

Kitchin, R. (2014, September 3-4). From a single line of code to an entire city: reframing thinking on code and the city. [working paper 4] Proceedings of code and the city workshop. The Programmable City Working Paper 4_NIRSA, National University of Ireland Maynooth. https://papers.ssrn.com/sol3/papers.cfm?abstract_id=2520435

Lemos, A. (2008) Mídias locativas e territórios informacionais. In L. Santaella \& P. Arantes (eds.). Estéticas Tecnológicas: Novos Modos de Sentir (pp. 207-230). São Paulo, Educ.

Lemos, A. (2013a). Cibercultura: Tecnologia e vida social na cultura contemporânea (6a ed.). Porto Alegre: Sulina. 
Lemos, A. (2013b). A comunicação das coisas: Teoria ator-rede e cibercultura. São Paulo: Annablume, 2013b.

Lemos, A. \& Firmino, R. (2015). I connect, therefore I am!: places, locales, locations and informational territorialization. Estudos do século XX, 15, 17-34. https://digitalis-dsp. uc.pt/jspui/bitstream/10316.2/38250/6/I\%20connect\%20therefore\%20I\%20am. pdf?ln=pt-pt

Liu, Y. \& Shrum, L. J. (2002). What is interactivity and is it always such a good thing? Implications of definition, person, and situation for the influence of interactivity on advertising effectiveness. Journal of Advertising, 31(4), 53-64. http://www.tandfonline. com/doi/abs/10.1080/00913367.2002.10673685

Luque-Ayala, A. \& Marvin, S. (2015). Developing a critical understanding of smart urbanism? Urban Studies, 52(12), 2105-2116. http://journals.sagepub.com/doi/ $\mathrm{abs} / 10.1177 / 0042098015577319$

Peck, J. \& Tickell, A. (2002). Neoliberalizing space. Antipode, 34(3), 380-404. https://doi. org/10.1111/1467-8330.00247

Pimenta, R. D. H. (2016, September). Pokémon Go: imersão, publicidade e ludicidade em um novo modelo de compra e inserção de mídia. Proceedings of XXXIX Congresso Brasileiro de Ciências da Comunicação. São Paulo,. http://portalintercom.org.br/anais/ nacional2016/resumos/R11-2966-1.pdf

PNAD - Pesquisa Nacional por Amostra de Domicílios (2016). Acesso à internet e televisão e posse de telefone móvel celular para uso pessoal: 2014. Instituto Brasileiro de Geografia e Estatística (IBGE) - Coordenação de Trabalho e Rendimento. Rio de Janeiro: IBGE, 2016. http://www.ibge.gov.br/home/estatistica/populacao/acessoainternet2014/ default.shtm

Prefeitura de Curitiba. (2014). População tem nova ferramenta de comunicaçấo com a Prefeitura. Notícia publicada em 28 de março de 2014. http://www.curitiba.pr.gov.br/ noticias/populacao-tem-nova-ferramenta-de-comunicacao-com-a-prefeitura/32421

Santaella, L. (2008). Mídias locativas: a internet móvel dos lugares e coisas. Revista Famecos, 15(35), 95-101. http://revistaseletronicas.pucrs.br/ojs/index.php/revistafamecos/ article/view/4099

Santos, M. (2008). A natureza do espaço ( $4^{a}$ ed.). Sáo Paulo: Editora da Universidade de São Paulo (EDUSP).

Scott, R. (1982). Blade Runner, o caçador de androides. [filme] Burbank: Warner Bros Pictures.

Silva, M. (2009). O que é interatividade. Boletim Técnico do senac. http://www.senac.br/ informativo/bts/242/boltec242d.htm

Sola, J. C. (2014). El imaginario social de la democracia en Black Mirror. Revista Latina de Sociología RELASO, 4, 90-109. http://revistas.udc.es/index.php/RELASO/article/view/ relaso.2014.4.1.1223/299mar./2017.

The New York Times. (2016, July 11). Pokémon Go brings augmented reality to a mass audience. By Nick Wingfield and Mike Isaac. http://www.nytimes.com/2016/07/12/ technology/pokemon-go-brings-augmented-reality-to-a-mass-audience.html?_r=0

Vega-Barbas, M., Casado-Mansilla, D., Valero, M. A., López-de-Ipina, D., Bravo, J. \& Florez, F. (2012). Spaces and smart objects interoperability architecture (S3OiA). Proceedings of the 6th International Conference on Innovative Mobile and Internet Services in Ubiquitous Computing (pp. 725-730). USA, IEEE. http://ieeexplore.ieee.org/document/6296944/ 
Wachowski, L. \& Wachowski, L. (1999). Matrix. [filme]. Burbank: Warner Bros Pictures.

Weiser, M. (1991). The computer for the 21st Century. Scientific American 1991, 94-110. https://doi.org/10.1038/scientificamerican0991-94

Wertheim, Margaret. (2001). Uma história do espaço de Dante à internet. Rio de Janeiro: Jorge Zahar. 